\title{
Research on the Teaching of Career Course of Internet plus problem
}

\author{
Liu Ningfang ${ }^{1}$ and Zhang Ninghui ${ }^{1},{ }^{2}$ Le Guiqi \\ ${ }^{1}$ Jiangxi Science and Technology University \\ ${ }^{2}$ Nanchang Education Science Research Institute
}

Keywords: Internet +; problem-oriented; teaching mode

\begin{abstract}
Multimedia computer and network communication technology has changed people's ways of working, learning and living. Teaching which is centered on teachers as well as knowledge and skills is changing to be students-centered and problem-oriented, and to be the teaching mode of focusing on cultivating students' self-learning ability, which has gradually become the direction for teachers to explore and practice and is popular among students. With "problems" oriented, the author uses the modern information platform to try the teaching mode of "independent learning + group preparation for lessons + speech interaction + teacher comments", cultivating students' independent learning ability, communication skills, spirit of unity and cooperation and the abilities to analyze and solve problems, and has achieved good teaching results through three rounds of teaching practice and improvement.

Since1990s, the rapid development of multimedia computer and network communication technology has significant revolutionary influence on the work, study and daily life of people. The teaching mode of taking students as the center and cultivating their autonomous learning ability is becoming the direction of exploration and practice of more and more teachers', which is very popular among the students. Career education not only started late in our country with little school carrying out it, but the goal of career education is not clear and the content of it is relatively simple. The author tries to make the teaching design of the career course by using the modern information platform and taking "problem" as the orientation in order to cultivate students' ability to raise, analyze and solve problems, and has achieved good teaching effect after three rounds of teaching practice and improvement.
\end{abstract}

\section{The Characteristics of Problem Oriented Teaching}

1. The construction of the leading position of teachers and the dominant position of students. Problem oriented teaching has changed the teachers as the main part in the classroom, but strengthens the leading position of teachers and the dominant position of students during classroom teaching. The effective way to change the classroom teaching from teaching knowledge to teaching students' autonomous learning ability is to take the problem as the guide and cultivate the students' problem consciousness". And it's also conducive to attract students to participate in a wide range in the teaching process to achieve the effect of happy and positive learning.

2. A teacher is a guide of the study of a student. The key to success or failure of problem oriented teaching lies in the transformation of the teachers' role, which requires teachers to construct the classroom teaching mode to guide students into the realm of research gradually according to the cognitive rules and learning characteristics of students.

3. Students are active participants in the study. The student's subjectivity, namely, the classroom teaching should start from the development of the students and take motivating the internal driving force of the students to explore the problem as the ultimate goal of teaching, and the teachers should also give students more space to further participate in and create expression while imparting knowledge and skills.

\section{The Design of Problem Oriented Teaching}

Problem - oriented career course teaching mainly includes: four teaching links of autonomous learning, group preparing, lectures interactive and teacher reviews combines "Three Basics", the 
basic knowledge, basic theory, basic skills training of students and their active participation in each link of the course learning organically, which has become the core of teaching design. Follow the gradual logic of "what", "why", "how", and "if" and the specific requirements of each teaching link:

1. Autonomic learning. To solve the problem of "what is"? In order to urge students to develop autonomous learning habits and to detect the effect of students' autonomous learning, teachers can view student's self learning situation and their feedback of problem in self learning with the aid of the blue Moyun classes online network platform to have unified management of the students' self learning process.

2. Group preparing. Solve the problem of "why"? Teachers should carefully created situations, cases according to the characteristics of the course and the problems of students' self learning feedback form for the students to analyze and discuss in the group preparation.

3. Lectures interactive. Solve the problem of "how"? The whole class exchange solutions to solve the problem: at first, the representative of the preparing group makes a keynote speech through the course-ware by integrating the results of lesson preparation using information technology; at second, test the students' understanding of basic concepts and theories in class; then, the students can question and debate on the keynote speech; at last, the teacher can inspire students to think actively in terms of key points, difficulties and problems reflected in the classroom test combined with the firsthand experience.

4. Teacher reviews. Solve the problem of "if"? The teacher can review the student's understanding and view before the end of the teaching activity.

\section{Problems Oriented Teaching Practice and Result Analysis}

1. The lesson form. Career education curriculum is a public elective course open to all grades students from all majors, and each elective course of school includes a total of 30 hours and 10 times teaching activities, which cost 3 hours each time. According to the requirements of the teaching of elective courses, set up 4 teaching topics, and make autonomous learning package on each topic for students. The 1st, 3rd, 5th, 7th, 9th, and 10th teaching activities are for the whole class, thus all the students have to attend. And the 2nd, 4th, 6th, and 8th teaching activities are for the small class preparation, the students within same lesson preparation group attend each time. During the 1st teaching activity, teachers should introduce the course overview and learning materials package of each topic, and suggest students to choose inquiry content and the subject of presentation according to their interests and to form lesson preparation group voluntarily. The whole class is divided into 4 groups, and each of them conduct in-depth inquiry corresponds to one topic. In the3rd,5th,7th,and 9th teaching activities, at first, the representative of each preparing group makes a keynote speech through the course-ware; at second, The whole class question and reply to the related questions around the theme of the speech; then, teachers guide and review opinions and questions of students. In the 10th teaching activity, arrange the course assessment by taking the form of display and communication of students' application results, and taking project design study, implementation strategy application and video production quality as the main observation point for teachers to evaluate the effectiveness of learning.

2. Experimental subject. In order to compare the effect of problem oriented teaching, 120 students in a college career education class were randomly divided into two classes with 60 students in each one, and class one was the experimental group and class two is the control group. Using the natural experimental method, the experimental group used the problem oriented teaching mode and the control group used the traditional theory teaching mode.

3. Questionnaire design. After the end of the experimental course, compare and analyze the effects of teaching through a questionnaire survey and other methods, and analyze the improvement of students in three fields of emotion, cognition, and practice.

Based on the Questionnaire of the Teaching Effect of Career Planning Course of College Experience of Le Xiaorong from East China Normal University, the questionnaire was re-designed after soliciting expert opinion. Questionnaire was used to study the above three fields, each of which consists of three sub problems, and the design of all the nine questions adopted the form of 
single election; the score was given according to the compliance of answer to the question respectively, and the measurement results would get from the total score, namely, the higher the score was, the better the teaching effect would be. Before the survey, inform each informant of the purpose of the investigation, explain in detail, clear the meaning of each item, and require them to fill the true without signature. The results are as follows:

Table1 The selection of experimental group and control group in emotion field $(n=60)$

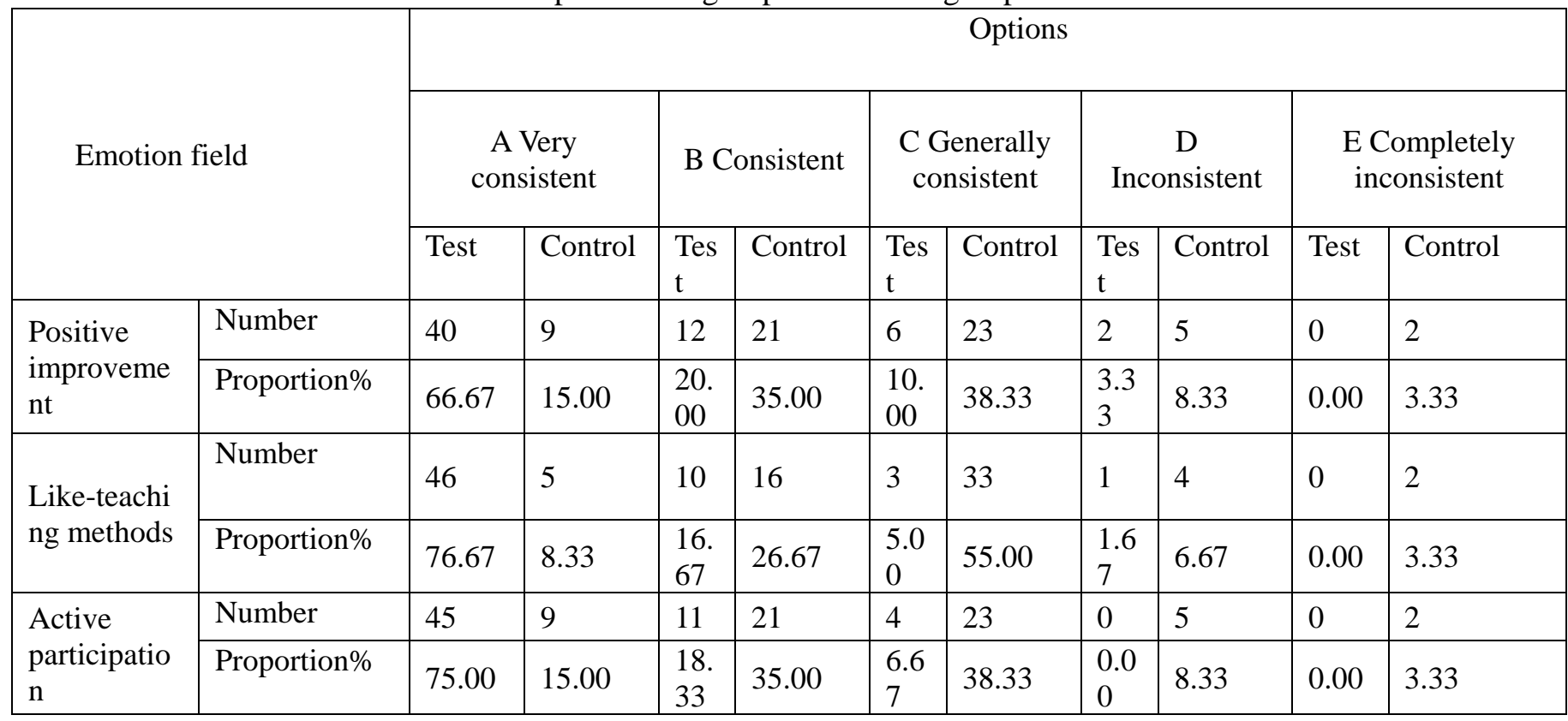

Table2 The selection of experimental group and control group in cognition field $(\mathrm{n}=60)$

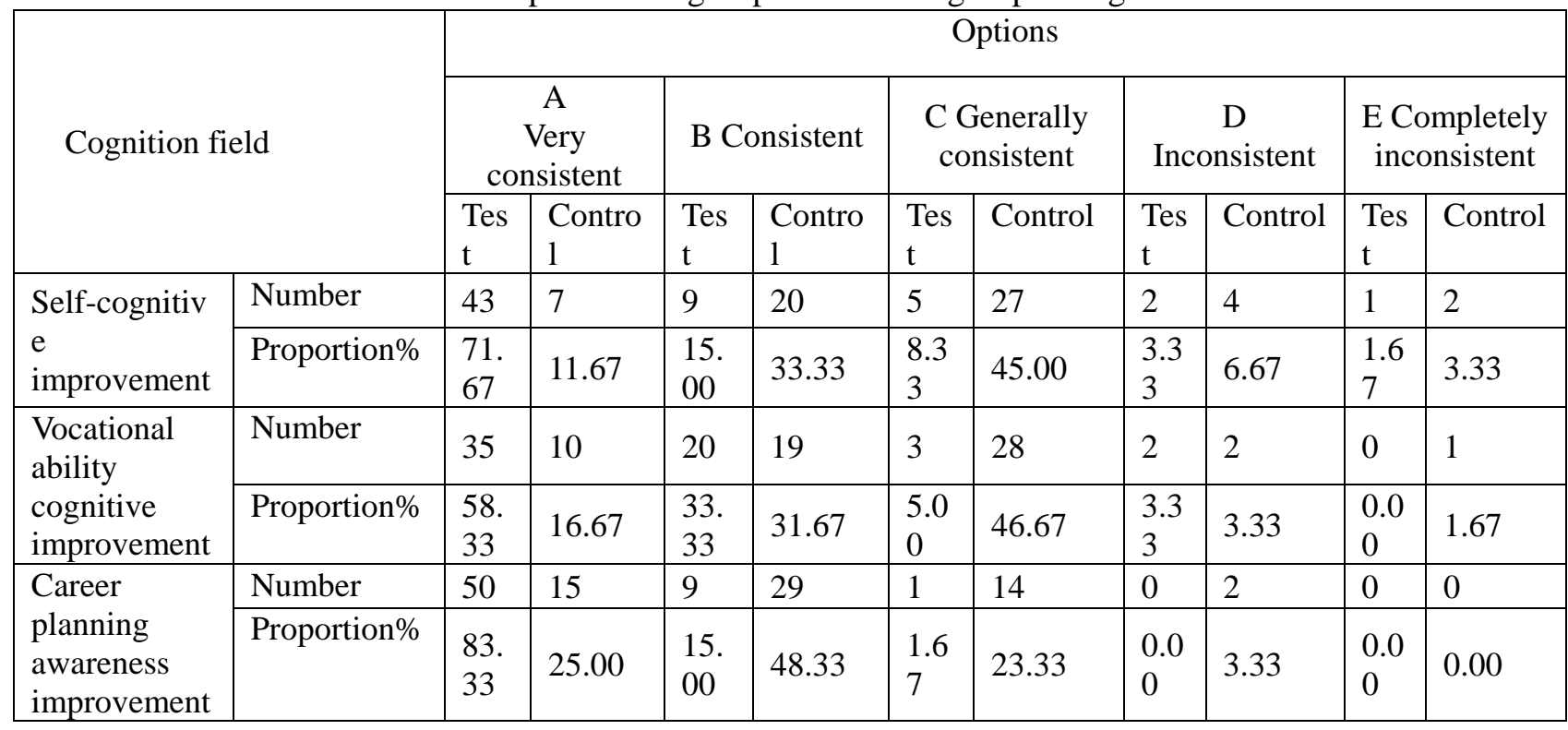


Table3The selection of experimental group and control group in practice field $(n=60)$

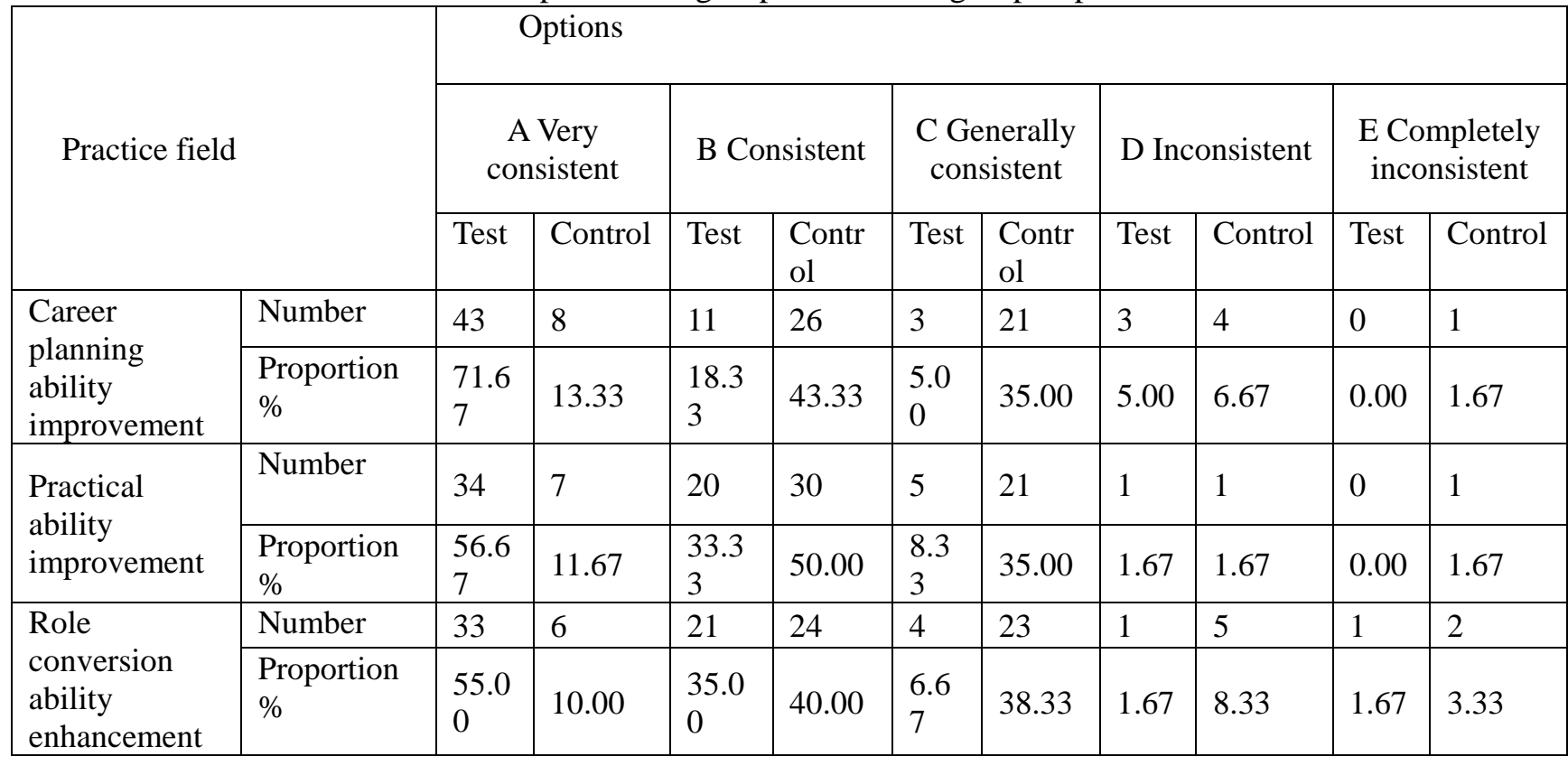

Table 4 Comparison of total scores of experimental group and control group

\begin{tabular}{|c|c|c|}
\hline \multirow{2}{*}{ Total scores } & \multicolumn{1}{|c|}{$\begin{array}{c}\text { Experimental } \\
\text { group }\end{array}$} & Control group \\
\cline { 2 - 3 } & 2465 & 1920 \\
\hline
\end{tabular}

The experimental results show that both of the two teaching modes have certain teaching effects, and the number of the students who are inconsistent and completely inconsistent is quite small. However, compared with the traditional teaching mode, it is not difficult to find that the students in the experimental group are mainly distributed in the 'very consistent', while the students in the control group are mainly distributed in the 'consistent' and 'generally consistent' items. So the problem oriented teaching model of the experimental group has better teaching effect and teaching quality, which also has obvious improvement of students in all aspects.

4. Analysis of students' interview. After the problem oriented teaching, the author made an face-to-face interview with the students about their feeling in the experimental group to collect their opinions by setting three questions of "what's your evaluation on teaching methods, attitude, content of the teacher?", "what's the class are you mostly impressed with?", "what do you harvest from problem oriented teaching?", and now the feedback information is sorted as follows:

(1). The teaching method is fresh but with pressure. After interviews with some students, it was learned that it was the first time for most of the students to participate in this kind of question oriented teaching mode, which makes them feel very fresh and feel under a lot of pressure, and they didn't prepare very well to participation experience. For examples:

Student A: I have never been in contact with this more open class, and I feel this is a very rare opportunity to exercise myself.

Student F: I select this lesson randomly at the beginning, while I benefit a lot from this class later, and we take activities in group as a whole so no one dare to slack off in case pull the team back with great pressure.

Student K: I prefer this teaching mode individually and appreciate teachers dare to innovate very much.

Student Q: Each class should be well-prepared for the teacher always raises some abrupt questions, so I need to be preoccupied with the preparation.

Student Y: I thought career planning class is pure theory class previously and did not expect to have so many tricks, so I like the teaching mode of this class very much.

(2). The teaching content is rich and fruitful. The students not only learn rich theoretical knowledge, but also exercise the ability to interact with people. For examples:

Student T: I never know that the need of measurement tools to know about myself but now can 
use a variety of measurement tables to measure my own personality, hobbies, temperament and so on.

Student B: In class, we often participate in activities in group and collect information, prepare lessons, discuss together so we soon become good friends.

Student X: In class, the teacher taught us a lot of knowledge that we cannot get from textbook, which broadened our horizon and made us have a new understanding of the outside world.

Student W: We used to jokingly call "the knowledge is returned to the teacher", but in the problem oriented teaching, the knowledge taught by the teacher are deeply engraved in our mind.

Student R: I knew very little about career planning before but after this class, I realize that we should begin to prepare even when we are freshmen to understand ourselves and exercise our ability.

(3). Improve the interest to learn, arouse the enthusiasm to participate, and promote the initiative of the students to experience. For examples:

Student $\mathrm{H}$ : Before in class, the teacher gave a lesson with a look of exultation on the podium while we were drowsy but we all can participate in teaching activities actively in the problem oriented teaching.

Student S: I feel that I was able to learn more things driven by problems, which is more effective than being forced to accept the knowledge infusion of the teacher.

Student J: Sometimes the teacher will give us some real cases of other people or let us play the role of the game, and I was very excited about every class to expect the teacher's new idea.

Student K: Since the first time to stand on the podium to share my feelings, I can take the initiative to participate in class activities each time and have great interest in career planning.

Student L: Never know learning can be such a happy thing and can learn the importance and necessity of life planning in the game.

(4). Students prefer to experience the participation by themselves and the impression will be more profound. The summary of the interview on "what's the class are you mostly impressed with?" shows that $99 \%$ of all the students are impressed with the teaching activities they take part in and very few students were impressed by the pure theoretical teaching of the teacher.

Student D: I was deeply impressed with a lesson the teacher conduct a "professional values evaluation" on us, and during the process I gradually clear my own professional values and recognize the most valued professional elements of my own.

Student Z: I was impressed deeply with playing the role of an applicant in simulated recruitment in order to recognize my own shortcomings and the gap with others through the simulated recruitment.

Student R: I was impressed deeply with the first time to teach PPT produced by our group, and I became more confident after stepping out the first step bravely.

Student T: I was impressed deeply with a video played by the teacher in class, whose content is the interviews on career planning of several successors, and I learned how to plan my own life through their real case study.

\section{Brief Summary}

Problem oriented teaching practice shows that around the questions in terms of the key points of the course content raised by the teacher, students have a preliminary understanding on related theory and academic dynamics according to teaching requirements through autonomous learning and group discussion and so on, and form some new "problems" in the process of learning and thinking. Teachers inspire students to think and invoke their inspirations according to the new questions raised by the students. The speech interaction of students will further deepen the thinking of the problem; at last, teachers review on the discussion of the students and puts forward some problems about "how", and usually the introduction of method is more effective than the description of point of view for the former is to guide students to explore the entrance to solve the problem while the latter is to tell the students where the results are. 
In addition, it is necessary to provide students with the information package and space for students interaction and teachers-students interaction with the help of information platform to ensure the self study of students is specific and effective and ensure the students can get help timely and conveniently from students and teachers in the autonomous learning process when they are faced with difficulties and problems, which can improve students' autonomous learning efficiency, and enhance students' autonomous learning interest and confidence.

Project source: Provincial project of research on the teaching reform of higher education in Jiangxi Province in 2014, project number: JXJG-14-10-18; the key project of the "12th Five-Year" planning of Jiangxi Province Education Science in 2015, number is: 15ZD3LYB048.

\section{References}

[1]Education Department. Development Plan of Education Information in 10 Years (2011-2020)[EB/OL], 2012.

[2] Luo Yongwei. Design of "problem centered" teaching mode[J].Research on Adult Education in China, 2006,(2).

[3] Ma Xiulin, Zhao Guoqing, Wu tong.An empirical study on the public classteaching flipped by information technology in University [J]. Journal of Distance Education, 2013.

[4]Yu Wensen.Three connotation of effective teaching and its significance[J]. Journal of the Chinese Society of Education,2012.

[5]Nan Hai, Li Jinbi.What is "career" -- the cognition of the concept of "career"[J].Chinese Vocational and Technical Education,2006,(33).

[6]Shen Zhifei. Career counseling[M].Shanghai:Shanghai Education Press,2000.

[7]Yang Jiumin.Modern educational technology[M].Wuhan:Huazhong Normal University press,2007. 